\title{
Regulatory roles of microRNA-21 in fibrosis through interaction with diverse pathways (Review)
}

\author{
RONG-HAN LIU* ${ }^{*}$, BIN NING ${ }^{*}$, XIAO-EN MA, WEI-MING GONG and TANG-HONG JIA \\ Department of Spinal Surgery, Jinan Central Hospital Affiliated to Shandong University, Jinan, Shandong 250013, P.R. China
}

Received February 27, 2015; Accepted January 5, 2016

DOI: $10.3892 / \mathrm{mmr} .2016 .4834$

\begin{abstract}
MicroRNA-21 (miR-21) is a small, non-coding RNA which can regulate gene expression at the post-transcriptional level. While the fibrogenic process is vital in tissue repair, proliferation and transition of fibrogenic cells combined with an imbalance of secretion and degradation of the extracellular matrix results in excessive tissue remodeling and fibrosis. Recent studies have indicated that miR-21 is overexpressed during fibrosis and can regulate the fibrogenic process in a variety of organs and tissues via diverse pathways. The present review summarized the significant roles of miR-21 in fibrosis and discussed the underlying key pathways.
\end{abstract}

\section{Contents}

1. Introduction

2. $\operatorname{miR}-21$

3. Expressional changes of miR-21 in fibrosis

4. Signaling pathways associated with miR-21 in fibrosis

5. Functions of miR-21 in various organs and tissues

6. Conclusions and perspectives

\section{Introduction}

MicroRNAs (miRs) are a class of small (18-22 nucleotides long), non-coding, evolutionarily conserved RNA molecules, which are significant regulators of gene expression at the post-transcriptional level though inhibiting the translation of messenger RNA (mRNA) and/or destroying the complete structure of mRNA $(1,2)$. Since the first discovery of miR in 1993 (3), miRs have been identified as a distinct type of epigenetic regulators in the early 2000s (4-6), and 28,645 miRs have

Correspondence to: Professor Tang-Hong Jia, Department of Spinal Surgery, Jinan Central Hospital Affiliated to Shandong University, 105 Jiefang Road, Jinan, Shandong 250013, P.R. China

E-mail: jiatanghong@hotmail.com

${ }^{*}$ Contributed equally

Key words: microRNA-21, fibrosis, pathway been identified to date. Studies have confirmed that miRs exert a variety of biological functions in various organs or tissues, which are associated with development, cell proliferation, cell growth and differentiation $(1,2)$. The expression of several of these miRs has been identified to be dysregulated in various diseases (7-9).

Fibrosis is a reparative or reactive process, which occurs following wounds, burns, trauma, surgery or disease. In order to repair the damage and prevent infection, fibrogenic cells, including fibroblasts, increase their secretion capacity and form fibrous connective tissue. This process forms a scar to aid recovery. However, the formation of excess fibrous connective tissue has a negative effect on healing (10). Fibrous connective tissue is characterized by excessive and persistent accumulation of extracellular matrix (ECM) proteins. The imbalance between secretion and degradation of ECM results in tissue remodeling and fibrosis, which eventually impairs the function of the affected organ. The ECM is composed of a variety of proteins, including composition-like collagens (Cols), fibronectin (FN) and laminin. Fibrosis occurs in a variety of organs and tissues and the recovery of dysfunction requires long-term recovery. Studies have shown that the activation, proliferation and differentiation of fibrogenic cells participates in the development of fibrosis. Epithelial-to-mesenchymal transition (EMT) is a process required for the development of fibrosis (11), during which epithelial cells lose their epithelial cell-specific markers and start to express fibroblast-specific markers (12), including $\mathrm{N}$-cadherin and vimentin (13). Furthermore, the process of endothelial-to-mesenchymal transition (EndMT) also contributes to fibroblast formation in fibrotic diseases in various types of tissues and organs, including the heart $(14,15)$, kidney (16), lung (17) and liver (18). Fibroblasts are the major cell type in fibrosis and their differentiation into myofibroblasts enhances their fibrogenicity (19). In addition, epithelial cells undergoing EMT have been reported to be potential sources of myofibroblasts in lung $(20)$, renal $(21,22)$ and hepatic $(18,23)$ fibrosis. These activated fibroblasts promote the secretion of ECM of fibrotic cells as well as their proliferation and survival.

In recent years, studies have focused on the effects of miRs on fibrosis, and the number of miRs with proven regulatory roles in fibrosis is increasing. For instance, miR-133 has been discovered to be linked with cardiac fibrosis and regulates fibroblast signatures though various signaling pathways $(24,25)$. In pulmonary fibrosis, miR-92a regulates the expression of the matricellular protein WNT1-inducible 
signaling pathway protein 1 via the transforming growth factor beta (TGF- $\beta$ ) signaling pathway (26). The application of miRs to prevent fibrosis in a clinical setting has also been indicated, as miR-29b effectively inhibited fibrosis in mice subjected to peritoneal dialysis (27). Numerous further miRs, including miR-200, miR-29, miR-155 and miR-133, have been reported to be associated with cardiovascular diseases and fibrosis $(28,29)$. Among these, miR-21 has become the focus of research on the pathophysiology of disease, particularly fibrosis in various organs and tissues.

\section{2. $\mathrm{miR}-21$}

miR-21 is a small, but crucial regulatory RNA in a large variety of physiological and pathological processes. Human miR-21 is a polycistronic miRNA whose gene is located in chromosome 17q23.2, where it overlaps with the protein-coding gene VMP1, also known as TMEM49. As for all miRs, the expression of miR-21 is regulated at the post-transcriptional level by a variety of regulatory proteins, including TGF- $\beta$ receptor (TGF- $\beta$ R), phosphatase and tensin homologue (PTEN) and Smad7 $(30,31)$.

The expression of miR-21 has been assessed in numerous human diseases, particularly in tumors (32). In addition, aberrantly expressed miR-21 has been found to promote fibrogenic activation of fibroblasts $(33,34)$. miR-21 is able to regulate protein expression in multiple organs and tissues and has an impact on tumor development, cancer, inflammation and the immune system (30,35-38).

\section{Expressional changes of miR-21 in fibrosis}

miR-21 is widely expressed, and has been detected to be increased in organs and tissues which have suffered fibrogenesis, including the heart, kidneys, lungs, skin and tumors $(32,33,39-44)$. In mice, miR-21 was found to be overexpressed in cardiac fibroblasts after myocardial ischaemia/reperfusion (44). It was also indicated that miR-21 may contribute to pathological cardiac remodeling and the development of fibrosis $(33,45)$. The increased expression of miR-21 in lung fibrosis has been indicated to promote EMT of lung epithelial cells (46). miR-21 was also found to be overexpressed in tubular epithelial cells after renal ischemia/reperfusion injury to protect them from death, which may promote the occurrence of renal fibrosis $(47,48)$. In kidney fibrosis, miR-21 was overexpressed not only in primary fibroblasts, but also elevated in the blood (49). Traumatic injury of the central nervous system was shown to increase the levels of miR-21 in the lesion area $(7,50)$. miR-21 may protect neurons by exerting anti-apoptotic effects (51). Studies have revealed that miR-21 may regulate the astrocytic response to nervous system injuries and protects fibroblasts to inhibit glial scar formation $(52,53)$. Furthermore, elevated miR-21 expression has been detected in the liver following experimental hepatic fibrosis, while its inhibition with 3,3'-diindolylmethane ameliorated fibrosis $(54,55)$. Skin wound healing is another fibrotic process, and enhanced fibroblast proliferation occurs in the hyperplastic scar. The expression of miR-21 in hyperplastic scars has been shown to be elevated compared to that in normal skin (56). In addition, miR-21 was found to be implicated in the proliferation of human keloid fibroblasts by directly targeting PTEN (57). Furthermore, miR-21 was shown to have a role in scleroderma fibrosis and was overexpressed in the skin of mice with radiation-induced fibrosis $(39,58)$. In summary, miR-21 overexpressed in fibrotic tissues and has a significant function in the development of fibrosis; however, the underlying molecular mechanisms vary in different organs or tissues.

\section{Signaling pathways associated with miR-21 in fibrosis}

miR-21 affects the expression of a variety of proteins via binding to the 3'-untranslated region (3'-UTR) of their respective mRNAs, resulting in a complex interaction network due to various downstream effects on signaling pathways (59). To date, several signaling pathways has been identified to be involved in the pathophysiological processes of fibrosis, among which the TGF- $\beta /$ Smads, phosphoinositide 3-kinase (PI3K)/AKT and extracellular signal-regulated kinase $($ ERK)/mitogen-activated protein kinase (MAPK) signaling pathways have key roles.

TGF- $\beta /$ Smads signaling pathway. TGF- $\beta$ is well known as a pivotal mediator in the pathogenesis of fibrosis $(60,61)$. TGF- $\beta$ upregulates numerous genes associated with fibrogenesis and promotes the development of fibrosis via its downstream mediators, including Smad2 and Smad3, while fibrosis is inhibited by Smad7 (62-64). Deletion of Smad3 protects from fibrosis in mice (65). However, deletion of Smad2 significantly enhanced Smad3 expression, thereby leading to ECM expansion and fibrosis development, which indicated that Smad2 functions as a negative regulator of TGF- $\beta$ signaling (66). Activation of TGF- $\beta$ receptor by TGF- $\beta$ may induce the regulatory Smad 3 proteins, which then initiate Smad4-dependent transcription (63). Of note, TGF- $\beta 1$ is known to upregulate miR-21 expression (64). TGF- $\beta$ signaling and Smad 3 have important roles in miR-21 transcription, and Smad proteins control the maturation of miR-21 from pre-miR-21 $(64,67)$. Smad2 and Smad3 have opposite roles in regulating the biogenesis of miR-21 - Smad3 promotes, while Smad2 prevents the expression of pre-miR-21 after stimulation with TGF- $\beta(66,68)$. Smad7 is a direct target of miR-21 and is therefore depressed following upregulation of mature miR-21 $(38,69)$.

TGF- $\beta 1$ can induce the differentiation of fibroblasts into the more fibrogenic myofibroblasts (19). Its downstream mediator Smad3 was also shown to regulate the expression of Cols, fibronectin (FN), and $\alpha$-smooth muscle actin ( $\alpha$-SMA) directly, by binding to their promoters (62). $\alpha$-SMA has been proved to be critical for the trans-differentiation of hepatic stellate cells (HSCs) into myofibroblasts (70).

The crosstalk between miR-21 and the TGF- $\beta /$ Smads signaling pathway can regulate the fibrotic procedure though downstream proteins in a variety of signaling pathways.

PI3K/AKT signaling pathway. TGF- $\beta$ can activate PI3K/AKT signaling though inhibiting phosphatase and tensin homolog (PTEN) (71,72), and it is well known that PTEN is a negative factor of the PI3K/AKT signaling pathway $(73,74)$. The expression of fibrotic proteins mediated TGF- $\beta$, including FN and Cols, is regulated by PI3K/AKT signal transduction $(72,75)$. 


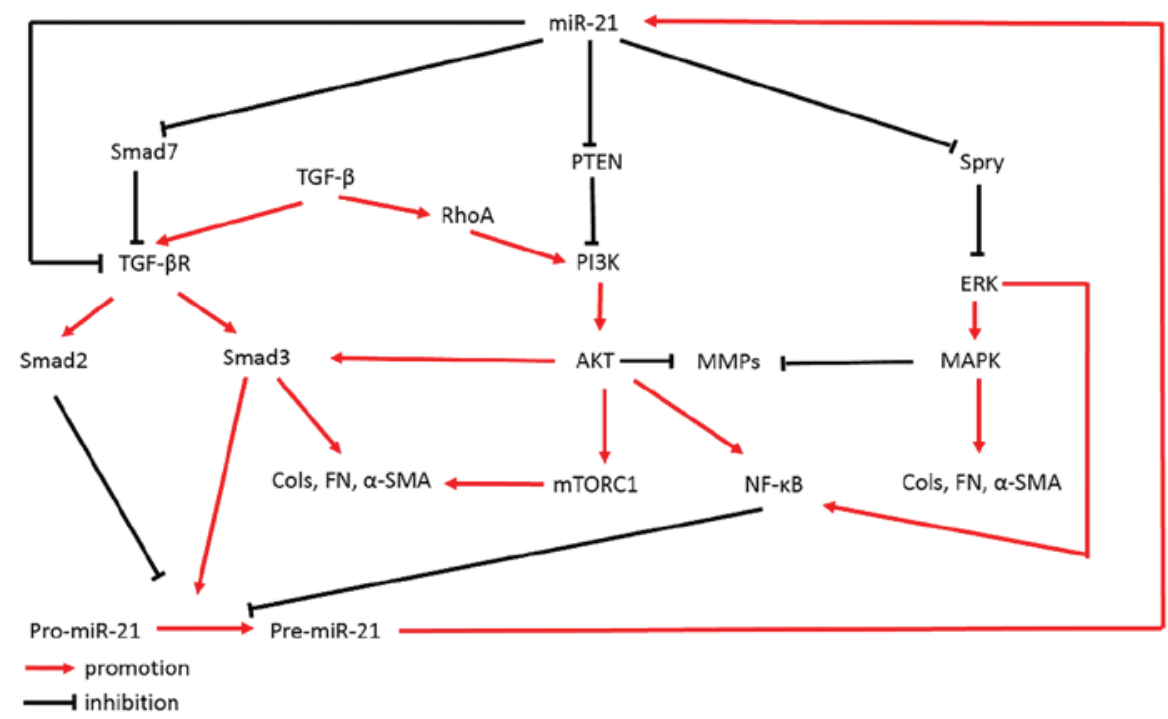

Figure 1. Interaction between miR-21 and diverse signaling pathways in the regulation of fibrosis. Schematic illustrating the feedback loop between miR-21 and diverse signaling pathways (TGF- $\beta$, PI3K/AKT or ERK/MAPK signaling pathway). miR, microRNA; TGF, transforming growth factor; MAPK, mitogen-activated protein kinase; ERK, extracellular signal-regulated kinase; PI3K, phosphoinositide-3 kinase.

TGF- $\beta$ has been demonstrated to regulate PI3K-dependent mammalian target of rapamycin (mTOR) to increase cellular hypertrophy (76-78). mTOR is a downstream protein of the PI3K/AKT signaling pathway. It has been shown that TGF- $\beta$ can activate PI3K/AKT signaling with targeting of PTEN, and RhoA may be an upstream mediator of Akt activation and involved in TGF- $\beta$-induced activation of PI3K/AKT signaling in response to TGF- $\beta 1$ (71). Akt activation has an important role in the EMT (79) as well as the EndMT (80), likely though the nuclear factor- $\kappa \mathrm{B}(\mathrm{NF}-\kappa \mathrm{B})$ pathway (79), as AKT signaling can activate NF- $\kappa B$ signaling (81). PTEN has been demonstrated to be a direct target of miR-21 $(34,74)$. In conclusion, miR-21 can regulate the process of fibrosis though PI3K/AKT signaling by targeting PTEN.

ERK/MAPK signaling pathway. ERK signaling is known to have a significant impact in fibrogenesis (82). Suppression of ERK expression can block EMT of hepatic fibrosis in rats (82). Sprouty (Spry) is a target of miR-21 $(32,83,84)$ as well as a potent inhibitor of the ERK/MAPK signaling pathway (74). Spry1 expression and MAPK signaling activation in the myocardium were completely reversed by treatment with an antagonist of miR-21 (32). In addition, miR-21 inhibitors have been shown to increase the mRNA transcript levels of Spry2 and significantly reduce the expression of profibrotic genes in activated HSCs, including TGF- $\beta 1, \alpha$-SMA and collagen (85). In addition, ERK signaling can activate the $\mathrm{NF}-\kappa \mathrm{B}$ signaling pathway (86). NF- $\kappa \mathrm{B}$ signaling was shown to inhibit miR-21 expression by binding directly to its promoter and regulate the process of arsenite-induced cell transformation (87).

Interaction network of miR-21. The signaling pathways of fibrosis are interconnected; for instance, the PI3K pathway positively regulates Smad3 transcription and increases Col production, suggesting that activation and interaction of diverse signaling pathways contributes to the pathogenesis of fibrosis (75) (Fig. 1). On the other hand, ERK signaling also interacts with AKT signaling through the NF- $\mathrm{BB}$ pathway, however, these pathways affect miR-21 production. In turn, miR-21 regulates these pathway through different target proteins. In conclusion, miR-21 may be a key factor in the interaction network.

It is worth mentioning that other targets of miR-21, including programmed cell death-4, tissue inhibitor of metalloproteinases-3 and reversion-inducing cysteine-rich protein with kazal motifs have functions in the migration and invasion of cancer cells or traumatic brain injury (88-90), and that these miR-21-mediated targets are negative regulators of matrix metalloproteinases (MMPs) (37,91-93). While the exact roles of miR-21 in these complex interactions remain to be fully elucidated, it has a key role in fibrosis through interlinking several fibrosis-associated pathways and is therefore a promising target for the treatment of fibrosis.

\section{Functions of miR-21 in various organs and tissues}

miR-21 has a key role in fibrosis though regulating fibrogenic cell activation, survival, secretion, hypertrophy and transition. It can promote the process of ECM formation and the EMT, leading to fibrosis development in a variety of tissues and organs (Table I) $(32,39-44,54,57,68,69,78,85,94-97)$.

Heart. The majority of cardiovascular diseases, including heart failure, myocardial infarction and atrial fibrillation, are associated with myocardial remodeling. Cardiac fibrosis is an important process in myocardial structural remodeling (98-100). miR-21 can control myocardial structural remodeling via several pathways. A study using a cardiovascular disease model demonstrated that cardiac stress can upregulate the expression of miR-21, which mediates the activation of ERK/MAPK signaling though targeting Spry1 to positively regulate cardiac fibroblast survival and growth factor secretion, resulting in fibrosis, remodeling and cardiac 
Table I. Function of miR-21 in various organs and tissues though diverse pathways.

\begin{tabular}{|c|c|c|c|c|c|}
\hline Organ & $\begin{array}{l}\text { Target } \\
\text { gene }\end{array}$ & Signaling pathway & Target cell type & Function & Ref \\
\hline \multirow[t]{5}{*}{ Liver } & Smad7 & TGF- $\beta$ signaling pathway & Hepatic stellate cells & EMT, ECM formation & (43) \\
\hline & Smad7 & TGF- $\beta$ signaling pathway & Hepatic stellate cells & Cell survival and proliferation & (54) \\
\hline & PTEN & PI3K/AKT signaling pathway & Hepatic stellate cells & EMT & (42) \\
\hline & PTEN & PI3K/AKT signaling pathway & Hepatic stellate cells & EMT, ECM formation & (94) \\
\hline & Spry2 & ERK/MAPK signaling pathway & Hepatic stellate cells & EMT, ECM formation & (85) \\
\hline \multirow[t]{4}{*}{ Heart } & Spry1 & ERK/MAPK signaling pathway & Fibroblasts & Cell survival and ECM formation & (32) \\
\hline & Spry1 & ERK/MAPK signaling pathway & Fibroblasts & Cell survival and ECM formation & (95) \\
\hline & PTEN & PI3K/AKT signaling pathway & Fibroblasts & $\begin{array}{l}\text { Cell hypertrophy and ECM } \\
\text { formation }\end{array}$ & (44) \\
\hline & TGF- $\beta$ R & TGF- $\beta$ signaling pathway & Fibroblasts & EMT, ECM formation & (96) \\
\hline \multirow[t]{3}{*}{ Kidney } & PTEN & PI3K/AKT signaling pathway & Mesangial Cells & $\begin{array}{l}\text { Cell hypertrophy and ECM } \\
\text { formation }\end{array}$ & (78) \\
\hline & PTEN & PI3K/AKT signaling pathway & Tubular epithelial cells & ECM formation & (41) \\
\hline & Smad7 & TGF- $\beta$ signaling pathway & Tubular epithelial cells & EMT, ECM formation & $(68,69)$ \\
\hline Lung & Smad7 & TGF- $\beta$ signaling pathway & Fibroblasts & EMT, ECM formation & (40) \\
\hline \multirow[t]{3}{*}{ Skin } & Smad7 & TGF- $\beta$ signaling pathway & Fibroblasts & EMT, ECM formation & (39) \\
\hline & PTEN & PI3K/AKT signaling pathway & Fibroblasts & Cell hypertrophy and survival & (97) \\
\hline & PTEN & PI3K/AKT signaling pathway & Fibroblasts & Cell survival and proliferation & (57) \\
\hline
\end{tabular}

miR-21 can regulate the development of fibrosis in various organs and tissues though diverse pathways (TGF- $\beta$, PI3K/AKT or ERK/MAPK signaling pathways) via different target genes (Smad7, PTEN, Spry, TGF- $\beta R$ ) and cell types (hepatic stellate cells, tubular epithelial cells, fibroblasts, mesangial cells). miR-21 decreases the expression of target genes and activates target cells. Target cells are converted into activated myofibroblasts, which are more fibrogenic, or promoted to survive hypertrophy and hyperplasia, leading to increased secretion and ECM formation. miR, microRNA; TGF, transforming growth factor; MAPK, mitogen-activated protein kinase; ERK, extracellular signal-regulated kinase; PI3K, phosphoinositide-3 kinase; EMT, epithelial-to-mesenchymal transition; ECM, extracellular matrix.

dysfunction; however, this process was inhibited by silencing of miR-21 (32). Similarly, a study on patients with atrial fibrillation showed that miR-21 was upregulated and Spryl was decreased (95). In mice, the increased expression of miR-21 and the decreased expression of Spry1 by angiotensin II contributed to fibroblast survival and structural remodeling in the atrial myocardium (95). Studies on other pathways have reported a variety of roles for miR-21. In the pathogenic process of myocardial fibrosis, miR- 21 and TGF- $\beta 1$ were shown to be upregulated, while TGF- $\beta$ RIII was downregulated (96). Overexpression of TGF- $\beta$ RIII inhibited the expression of miR-21 in fibroblasts, probably via phosphorylated Smad3. However, overexpression of miR- 21 induced by TGF- $\beta 1$ led to the differentiation of fibroblasts into pathological myofibroblasts and increased the Cols content. Fibrosis is therefore regulated by a reciprocal feedback loop between TGF- $\beta$ RIII and miR-21 (96). MMP-2 degrades the ECM and knocks down PTEN in cardiac fibroblasts, resulting in marked phosphorylation of AKT signaling and induction of MMP-2. In a murine model of myocardial infarction, miR-21 was shown to regulate MMP-2 expression in fibroblasts via PTEN, leading to cell hypertrophy and matrix protein expression (44). These findings may provide a direction for further studies.

Liver. miRs have been extensively studied in liver fibrosis, particularly the miR-29 family, miR-122 and miR-21 $(101,102)$.
Among them, miR-21 was found to have significant effects in the process of fibrosis development, while numerous risk factors, including hepatitis $\mathrm{C}$ virus (HCV), fatty liver, alcohol consumption and schistosome infection can cause fibrosis (54). The target cells in liver fibrosis are HSCs $(42,43,54,85,94,103)$, and activated HSCs are responsible for the imbalance of secretion and degradation of the ECM (104). Livers of mice and humans with hepatic fibrosis in non-alcoholic steatohepatitis have shown increased levels of miR-21 with co-localized overexpression of TGF- $\beta$, Cols, $\alpha$-SMA and Smad $2 / 3-\operatorname{Smad} 4$, while the protein levels of Smad7 were decreased (43). However, treatment with leptin-nicotinamide adenine dinucleotide phosphate oxidase reversed these effects in mice. Similar observations were made in HCV patients: miR-21 overexpression enhanced TGF- $\beta$ signaling, and Smad7 was a negative regulator of TGF- $\beta$ signaling in a positive feedback cycle to promote HSC survival and proliferation $(54,103)$. The fibrogenic role of miR-21 was also found in biliary atresia patients and in an in vitro experiment, which it exerted through the PTEN/AKT signaling pathway and targeting of PTEN. miR-21 was shown to activate AKT signaling via phosphorylation, alongside decreased expression of MMP-2 and increased expression of $\alpha$-SMA $(42,94)$, which indicated that miR-21 promotes the transdifferentiation of HSCs into myofibroblasts as well as ECM formation. HSCs are likely to be activated via various routes, including the ERK signaling pathway. miR-21 
directly interacts with the 3'-UTR of Spry2, resulting in enhanced ERK signaling in HSCs (85). Enhanced expression of $\alpha$-SMA and vimentin showed that miR-21 can regulate the EMT as well as ECM formation through ERK signaling (85).

Kidney. Renal fibrosis is characterized by an excess accumulation of ECM and myofibroblasts, as fibrosis in other organs, and features tubule atrophy. Gene therapy by Smad7 overexpression in obstructive nephropathy-induced fibrosis suppresses miR-21, Col, FN and $\alpha$-SMA (69). Furthermore, TGF- $\beta 1$ was shown to upregulate miR-21 expression via Smad3, but to downregulates it via Smad2 in tubular epithelial cells (TECs) (68). It is therefore indicated that miR-21 and its regulation via TGF- $\beta$ /Smads signaling has a significant role in renal fibrosis though ECM formation and EMT. Interstitial fibrosis and tubular atrophy influence renal outcomes of immunoglobulin (Ig)A nephropathy (105). A recent study on both podocytes and TECs of patients with IgA nephropathy showed that miR-21 expression was upregulated (41). Inhibition of miR-21 prevented fibrogenic activation in podocytes and TECs by reversing the overexpression of FN and Col though inhibiting AKT pathway activation. Another study has revealed that miR-21 can suppress the AKT pathway via its target PTEN and activate the downstream protein mTORC1, leading to hypertrophy of mesangial cells and matrix protein expression (78), as mesangial cells also take a vital role in renal fibrosis (61).

Lung. Like in other tissues and organs, TGF- $\beta 1$ is well known to be an important conditioner of lung fibrosis and can induce fibroblast-to-myofibroblast differentiation characterized by $\alpha$-SMA expression and high expression of ECM $(46,106)$. The EMT has a distinct role in lung fibrosis. In a study of idiopathic pulmonary fibrosis, miR-21 was shown to be highly expressed and primarily localized to myofibroblasts, alongside an increase in $\alpha$-SMA expression (40). The increased miR-21 promotes fibrogenic activity of TGF- $\beta 1$ in fibroblasts though regulating the expression of Smad7. Another study showed that miR-21 is upregulated in isolated lung epithelial cells induced by bleomycin. Furthermore, PTEN has been shown to have a negative regulatory role in experimental lung fibrosis (107).

Skin. Systemic sclerosis is known as a process of fibrosis with increased expression of miR-21 (39). TGF- $\beta$ is also implicated in the pathogenesis and progression of skin fibrosis (108). Normal skin fibroblasts incubated with TGF- $\beta 1$ showed overexpression of miR-21 (39). In bleomycin-treated mice, the pro-fibrogenic activity caused by $\alpha$-SMA and Cols overexpression stimulated by miR-21 was identified to be mediated via the TGF- $\beta$ signaling pathway by targeting Smad7 (39). Hypertrophic scarring, the most common type of skin disorder, occurs after abnormal wounding, and miR-21 has been reported to be of relevance in this process via the $\mathrm{PI} 3 \mathrm{~K} / \mathrm{AKT}$ signaling pathway through regulating the expression of human telomerase reverse transcriptase (hTERT) (97). It was revealed that fibroblasts transfected with PTEN showed decreased hTERT mRNA and protein expression. An identical mechanism was found to promote cell survival and proliferation in keloid fibroblasts (57).

\section{Conclusions and perspectives}

An increasing number of studies have demonstrated that miR-21 has a key role in fibrosis though regulating fibrogenic cell activation, survival, secretion, hypertrophy and transition. Previous studies suggested that targeting miR-21 may be an attractive method to inhibit the process of fibrosis.

The present review highlighted three signaling pathways via which miR-21 is involved in fibrosis, namely the TGF- $\beta /$ Smads, PI3K/AKT and ERK/MAPK signaling pathways, as well as their inhibitors Smad7, PTEN and Spry, which are also targets of miR-21. Of note, miR-21 has a key role in regulating the interaction of these pathways. The mechanisms presented in this review as well as their complex crosstalk are likely to be the key pathways underlying the role of miR-21 in fibrosis. Due to its key regulatory role in these processes, miR-21 is a potential target for the treatment of fibrosis.

\section{Acknowledgements}

The present study was supported in part by grants from the National Natural Science Foundation of China (grant no. 81401014) and the China Postdoctoral Science Foundation (grant no. 2014M561935).

\section{References}

1. Ambros V: The functions of animal microRNAs. Nature 431: 350-355, 2004.

2. Bartel DP: MicroRNAs: Genomics, biogenesis, mechanism, and function. Cell 116: 281-297, 2004.

3. Lee RC,Feinbaum RL and Ambros V: The C.elegans heterochronic gene lin-4 encodes small RNAs with antisense complementarity to lin-14. Cell 75: 843-854, 1993.

4. Reinhart BJ, Slack FJ, Basson M, Pasquinelli AE, Bettinger JC, Rougvie AE, Horvitz HR and Ruvkun G: The 21-nucleotide let-7 RNA regulates developmental timing in Caenorhabditis elegans. Nature 403: 901-906, 2000.

5. Lagos-Quintana M, Rauhut R, Lendeckel W and Tuschl T: Identification of novel genes coding for small expressed RNAs. Science 294: 853-858, 2001.

6. Lau NC, Lim LP, Weinstein EG and Bartel DP: An abundant class of tiny RNAs with probable regulatory roles in Caenorhabditis elegans. Science 294: 858-862, 2001.

7. Liu NK, Wang XF, Lu QB and Xu XM: Altered microRNA expression following traumatic spinal cord injury. Exp Neurol 219: 424-429, 2009.

8. Zhou J, Chaudhry H, Zhong Y, Ali MM, Perkins LA, Owens WB, Morales JE, McGuire FR, Zumbrun EE, Zhang J, et al: Dysregulation in microRNA expression in peripheral blood mononuclear cells of sepsis patients is associated with immunopathology. Cytokine 71: 89-100, 2015.

9. Zhang W, Zhou T, Ma SF, Machado RF, Bhorade SM and Garcia JG: MicroRNAs implicated in dysregulation of gene expression following human lung transplantation. Transl Respir Med 1: 1-12, 2013.

10. Birbrair A,Zhang T, Wang ZM, Messi ML, Mintz A and Delbono O: Type-1 pericytes participate in fibrous tissue deposition in aged skeletal muscle. Am J Physiol Cell Physiol 305: C1098-C1113, 2013.

11. Kalluri R and Neilson EG: Epithelial-mesenchymal transition and its implications for fibrosis. J Clin Invest 112: 1776-1784, 2003.

12. O'Connor JW and Gomez EW: Biomechanics of TGF $\beta$-induced epithelial-mesenchymal transition: Implications for fibrosis and cancer. Clin Transl Med 3: 23, 2014.

13. Lamouille S, Xu J and Derynck R: Molecular mechanisms of epithelial-mesenchymal transition. Nat Rev Mol Cell Biol 15: 178-196, 2014.

14. Zeisberg EM, Tarnavski O, Zeisberg M, Dorfman AL, McMullen JR, Gustafsson E, Chandraker A, Yuan X, Pu WT, Roberts $\mathrm{AB}$, et al: Endothelial-to-mesenchymal transition contributes to cardiac fibrosis. Nat Med 13: 952-961, 2007. 
15. Widyantoro B, Emoto N, Nakayama K, Anggrahini DW, Adiarto S, Iwasa N, Yagi K, Miyagawa K, Rikitake Y, Suzuki T, et al: Endothelial cell-derived endothelin-1 promotes cardiac fibrosis in diabetic hearts through stimulation of endothelial-to-mesenchymal transition. Circulation 121: 2407-2418, 2010.

16. Zeisberg EM, Potenta SE, Sugimoto H, Zeisberg M and Kalluri R: Fibroblasts in kidney fibrosis emerge via endothelial-to-mesenchymal transition. J Am Soc Nephrol 19: 2282-2287, 2008.

17. Hashimoto N, Phan SH, Imaizumi K, Matsuo M, Nakashima H, Kawabe T, Shimokata K and Hasegawa Y: Endothelial-mesenchymal transition in bleomycin-induced pulmonary fibrosis. Am J Respir Cell Mol Biol 43: 161-172, 2010.

18. Zeisberg M, Yang C, Martino M, Duncan MB, Rieder F, Tanjore $\mathrm{H}$ and Kalluri R: Fibroblasts derive from hepatocytes in liver fibrosis via epithelial to mesenchymal transition. J Biol Chem 282: 23337-23347, 2007.

19. Hinz B, Phan SH, Thannickal VJ, Galli A, Bochaton-Piallat ML and Gabbiani G: The myofibroblast: One function, multiple origins. Am J Pathol 170: 1807-1816, 2007.

20. Kim Y, Kugler MC, Wei Y, Kim KK, Li X, Brumwell AN and Chapman HA: Integrin alpha3beta1-dependent beta-catenin phosphorylation links epithelial Smad signaling to cell contacts. J Cell Biol 184: 309-322, 2009.

21. Li Y, Yang J, Dai C, Wu C and Liu Y: Role for integrin-linked kinase in mediating tubular epithelial to mesenchymal transition and renal interstitial fibrogenesis. J Clin Invest 112: 503-516, 2003.

22. Zeisberg M, Hanai J, Sugimoto H, Mammoto T, Charytan D, Strutz F and Kalluri R: BMP-7 counteracts TGF-beta1-induced epithelial-to-mesenchymal transition and reverses chronic renal injury. Nat Med 9: 964-968, 2003.

23. Rygiel KA, Robertson H, Marshall HL, Pekalski M, Zhao L, Booth TA, Jones DE, Burt AD and Kirby JA: Epithelial-mesenchymal transition contributes to portal tract fibrogenesis during human chronic liver disease. Lab Invest 88 : $112-123,2008$

24. Muraoka N, Yamakawa H, Miyamoto K, Sadahiro T, Umei T, Isomi M, Nakashima H, Akiyama M, Wada R, Inagawa K, et al: miR-133 promotes cardiac reprogramming by directly repressing Snai1 and silencing fibroblast signatures. EMBO J 33: 1565-1581, 2014.

25. Wang L, Li X, Zhou Y, Shi H, Xu C, He H, Wang S, Xiong X, Zhang Y, Du Z, et al: Downregulation of miR-133 via MAPK/ERK signaling pathway involved in nicotine-induced cardiomyocyte apoptosis. Naunyn Schmiedebergs Arch Pharmacol 387: 197-206, 2014.

26. Berschneider B,Ellwanger DC, Baarsma HA, Thiel C, Shimbori C, White ES, Kolb M, Neth P and Königshoff M: miR-92a regulates TGF- $\beta 1$-induced WISP1 expression in pulmonary fibrosis. Int J Biochem Cell Biol 53: 432-441, 2014.

27. Yu JW, Duan WJ, Huang XR, Meng XM, Yu XQ and Lan HY: MicroRNA-29b inhibits peritoneal fibrosis in a mouse model of peritoneal dialysis. Lab Invest 94: 978-990, 2014.

28. Drummond CA, Hill MC, Shi H, Fan X, Xie JX, Haller ST, Kennedy DJ, Liu J, Garrett MR, Xie Z, et al: Na/K-ATPase signaling regulates collagen synthesis through microRNA-29b-3p in cardiac fibroblasts. Physiol Genomics: Dec 23, 2015 (Epub ahead of print)

29. Patel V and Noureddine L: microRNAs and fibrosis. Curr Opin Nephrol Hypertens 21: 410-416, 2012.

30. Kumarswamy R, Volkmann I and Thum T: Regulation and function of miRNA-21 in health and disease. RNA Biol 8: 706-713, 2011.

31. Li YF, Jing Y, Hao J, Frankfort NC, Zhou X, Shen B, Liu X, Wang L and Li R: MicroRNA-21 in the pathogenesis of acute kidney injury. Protein Cell 4: 813-819, 2013.

32. Li Q, Zhang D, Wang Y, Sun P, Hou X, Larner J, Xiong W and Mi J: MiR-21/Smad 7 signaling determines TGF- $\beta 1$-induced CAF formation. Sci Rep 3: 2038, 2013.

33. Thum T, Gross C, Fiedler J, Fischer T, Kissler S, Bussen M, Galuppo P, Just S, Rottbauer W, Frantz S, et al: MicroRNA-21 contributes to myocardial disease by stimulating MAP kinase signalling in fibroblasts. Nature 456: 980-984, 2008.

34. Pandit KV, Milosevic J and Kaminski N: MicroRNAs in idiopathic pulmonary fibrosis. Transl Res 157: 191-199, 2011.

35. Meng F, Henson R, Lang M, Wehbe H, Maheshwari S, Mendell JT, Jiang J, Schmittgen TD and Patel T: Involvement of human micro-RNA in growth and response to chemotherapy in human cholangiocarcinoma cell lines. Gastroenterology 130: 2113-2129, 2006 .
36. Si ML, Zhu S, Wu H, Lu Z, Wu F and Mo YY: miR-21-mediated tumor growth. Oncogene 26: 2799-2803, 2007.

37. Ji R, Cheng Y, Yue J, Yang J, Liu X, Chen H, Dean DB and Zhang C: MicroRNA expression signature and antisense-mediated depletion reveal an essential role of MicroRNA in vascular neointimal lesion formation. Circ Res 100: 1579-1588, 2007.

38. Gabriely G, Wurdinger T, Kesari S, Esau CC, Burchard J, Linsley PS and Krichevsky AM: microRNA 21 promotes glioma invasion by targeting matrix metalloproteinase regulators. Mol Cell Biol 28: 5369-5380, 2008

39. Zhu H, Luo H, Li Y, Zhou Y, Jiang Y, Chai J, Xiao X, You Y and Zuo X: MicroRNA-21 in scleroderma fibrosis and its function in TGF- $\beta$-regulated fibrosis-related genes expression. J Clin Immunol 33: 1100-1109, 2013.

40. Liu G, Friggeri A, Yang Y, Milosevic J, Ding Q, Thannickal VJ, Kaminski N and Abraham E: miR-21 mediates fibrogenic activation of pulmonary fibroblasts and lung fibrosis. J Exp Med 207: 1589-1597, 2010.

41. Bao H, Hu S, Zhang C, Shi S, Qin W, Zeng C, Zen K and Liu Z: Inhibition of miRNA-21 prevents fibrogenic activation in podocytes and tubular cells in $\operatorname{Ig} \mathrm{A}$ nephropathy. Biochem Biophys Res Commun 444: 455-460, 2014.

42. Shen $W$, Chen $G$, Dong $R$, Zhao $R$ and Zheng $S$ : MicroRNA-21/PTEN/Akt axis in the fibrogenesis of biliary atresia. J Pediatr Surg 49: 1738-1741, 2014

43. Dattaroy D, Pourhoseini S, Das S, Alhasson F, Seth RK, Nagarkatti M, Michelotti GA, Diehl AM and Chatterjee S: Micro RNA 21 inhibition of SMAD7 enhances fibrogenesis via leptin mediated NADPH oxidase in experimental and human nonalcoholic steatohepatitis. Am J Physiol Gastrointest Liver Physiol 308: G298-G312, 2015.

44. Roy S, Khanna S, Hussain SR, Biswas S, Azad A, Rink C, Gnyawali S, Shilo S, Nuovo GJ and Sen CK: MicroRNA expression in response to murine myocardial infarction: miR-21 regulates fibroblast metalloprotease-2 via phosphatase and tensin homologue. Cardiovasc Res 82: 21-29, 2009.

45. Patrick DM, Montgomery RL, Qi X, Obad S, Kauppinen S, Hill JA, Van Rooij E and Olson EN: Stress-dependent cardiac remodeling occurs in the absence of microRNA-21 in mice. J Clin Invest 120: 3912-3916, 2010.

46. Yamada M, Kubo H, Ota C, Takahashi T, Tando Y, Suzuki T, Fujino N, Makiguchi T, Takagi K, Suzuki T and Ichinose M: The increase of microRNA-21 during lung fibrosis and its contribution to epithelial-mesenchymal transition in pulmonary epithelial cells. Respir Res 14: 95, 2013.

47. Godwin JG, Ge X, Stephan K, Jurisch A, Tullius SG and Iacomini J: Identification of a microRNA signature of renal ischemia reperfusion injury. Proc Natl Acad Sci USA 107: 14339-14344, 2010

48. Zarjou A, Yang S, Abraham E, Agarwal A and Liu G Identification of a microRNA signature in renal fibrosis: Role of miR-21. Am J Physiol Renal Physiol 301: F793-F801, 2011.

49. Glowacki F, Savary G, Gnemmi V, Buob D, Van der Hauwaert C, Lo-Guidice JM, Bouyé S, Hazzan M, Pottier N, Perrais M, et al: Increased circulating miR-21 levels are associated with kidney fibrosis. PLoS One 8: e58014, 2013.

50. Redell JB,Zhao J and Dash PK: Altered expression of miRNA-21 and its targets in the hippocampus after traumatic brain injury. J Neurosci Res 89: 212-221, 2011.

51. Buller B, Liu X, Wang X, Zhang RL, Zhang L, Hozeska-Solgot A, Chopp $\mathrm{M}$ and Zhang ZG: microRNA-21 protects neurons from ischemic death. FEBS J 277: 4299-4307, 2010.

52. Bhalala OG, Pan L, Sahni V, McGuire TL, Gruner K, Tourtellotte WG and Kessler JA: MicroRNA-21 regulates astrocytic response following spinal cord injury. J Neurosci 32: 17935-17947, 2012

53. Kimura-Kuroda J, Teng X, Komuta Y, Yoshioka N, Sango K, Kawamura $\mathrm{K}$, Raisman $\mathrm{G}$ and Kawano $\mathrm{H}$ : An in vitro model of the inhibition of axon growth in the lesion scar formed after central nervous system injury. Mol Cell Neurosci 43: 177-187, 2010.

54. Marquez RT, Bandyopadhyay S, Wendlandt EB, Keck K, Hoffer BA, Icardi MS, Christensen RN, Schmidt WN and McCaffrey AP: Correlation between microRNA expression levels and clinical parameters associated with chronic hepatitis $\mathrm{C}$ viral infection in humans. Lab Invest 90: 1727-1736, 2010.

55. Zhang Z, Gao Z, Hu W, Yin S, Wang C, Zang Y, Chen J, Zhang J and Dong L: 3,3'-Diindolylmethane ameliorates experimental hepatic fibrosis via inhibiting miR-21 expression. Br J Pharmacol 170: 649-660, 2013 
56. Ning P, Liu DW, Mao YG, Peng Y, Lin ZW and Liu DM: Differential expression profile of microRNA between hyperplastic scar and normal skin. Chin Med J 92: 692-694, 2012 (In Chinese).

57. Liu Y, Wang X, Yang D, Xiao Z and Chen X: MicroRNA-21 affects proliferation and apoptosis by regulating expression of PTEN in human keloid fibroblasts. Plast Reconstr Surg 134: 561e-573e, 2014.

58. Simone BA, Ly D, Savage JE, Hewitt SM, Dan TD, Ylaya K, Shankavaram U, Lim M, Jin L, Camphausen K, et al: microRNA alterations driving acute and late stages of radiation-induced fibrosis in a murine skin model. Int J Radiat Oncol Biol Phys 90 44-52, 2014

59. Jin L, Wu Z, Xu W, Hu X, Zhang J, Xue Z and Cheng L: Identifying gene expression profile of spinal cord injury in rat by bioinformatics strategy. Mol Biol Rep 41: 3169-3177, 2014

60. Meng XM, Huang XR, Xiao J, Chen HY, Zhong X, Chung AC and Lan HY: Diverse roles of TGF- $\beta$ receptor II in renal fibrosis and inflammation in vivo and in vitro. J Pathol 227: 175-188, 2012.

61. Schnaper HW, Hayashida T, Hubchak SC and Poncelet AC: TGF-beta signal transduction and mesangial cell fibrogenesis. Am J Physiol Renal Physiol 284: F243-F252, 2003.

62. Lan HY and Chung AC: Transforming growth factor- $\beta$ and Smads. Contrib Nephrol 170: 75-82, 2011.

63. Meng XM, Huang XR, Xiao J, Chung AC, Qin W, Chen HY and Lan HY: Disruption of Smad4 impairs TGF- $\beta /$ Smad3 and Smad7 transcriptional regulation during renal inflammation and fibrosis in vivo and in vitro. Kidney Int 81: 266-279, 2012.

64. Davis BN, Hilyard AC, Lagna G and Hata A: SMAD proteins control DROSHA-mediated microRNA maturation. Nature 454: $56-61,2008$.

65. Fujimoto M, Maezawa Y, Yokote K, Joh K, Kobayashi K, Kawamura H, Nishimura M, Roberts AB, Saito Y and Mori S: Mice lacking Smad3 are protected against streptozotocin-induced diabetic glomerulopathy. Biochem Biophys Res Commun 305: 1002-1007, 2003

66. Meng XM, Huang XR, Chung AC, Qin W, Shao X, Igarashi P, $\mathrm{Ju} \mathrm{W}$, Bottinger EP and Lan HY: Smad2 protects against TGF-beta/Smad3-mediated renal fibrosis. J Am Soc Nephrol 21: $1477-1487,2010$

67. Davis BN, Hilyard AC, Nguyen PH, Lagna G and Hata A: Smad proteins bind a conserved RNA sequence to promote microRNA maturation by Drosha. Mol Cell 39: 373-384, 2010.

68. Zhong X, Chung AC, Chen HY, Meng XM and Lan HY: Smad3-mediated upregulation of miR-21 promotes renal fibrosis. J Am Soc Nephrol 22: 1668-1681, 2011.

69. Chung AC, Dong Y, Yang W, Zhong X, Li R and Lan HY: Smad7 suppresses renal fibrosis via altering expression of TGF- $\beta$ /Smad3-regulated microRNAs. Mol Ther 21: 388-398, 2013.

70. Huang GC, Zhang JS and Tang QQ: Involvement of C/EBP-alpha gene in in vitro activation of rat hepatic stellate cells. Biochem Biophys Res Commun 324: 1309-1318, 2004.

71. Bakin AV, Tomlinson AK, Bhowmick NA, Moses HL and Arteaga CL: Phosphatidylinositol 3-kinase function is required for transforming growth factor beta-mediated epithelial to mesenchymal transition and cell migration. J Biol Chem 275 : 36803-36810, 2000.

72. Ghosh Choudhury G and Abboud HE: Tyrosine phosphorylation-dependent PI3 kinase/Akt signal transduction regulates TGFbeta-induced fibronectin expression in mesangial cells. Cel Signal 16: 31-41, 2004.

73. Maehama T and Dixon JE: The tumor suppressor, PTEN/MMAC1, dephosphorylates the lipid second messenger, phosphatidylinositol 3,4,5-trisphosphate. J Biol Chem 273: 13375-13378, 1998

74. Meng F, Henson R, Wehbe-Janek H, Ghoshal K, Jacob ST and Patel T: microRNA-21 regulates expression of the PTEN tumor suppressor gene in human hepatocellular cancer. Gastroenterology 133: 647-658, 2007.

75. Runyan CE, Schnaper HW and Poncelet AC: The phosphatidylinositol 3-kinase/Akt pathway enhances Smad3-stimulated mesangial cell collagen I expression in response to transforming growth factor-beta1. J Biol Chem 279: 2632-2639, 2004.

76. Mahimainathan L, Das F, Venkatesan B and Choudhury GG: Mesangial cell hypertrophy by high glucose is mediated by downregulation of the tumor suppressor PTEN. Diabetes 55: 2115-2125, 2006.

77. Lamouille S and Derynck R: Cell size and invasion in TGF-beta-induced epithelial to mesenchymal transition is regulated by activation of the mTOR pathway. J Cell Biol 178: 437-451, 2007
78. Dey N, Ghosh-Choudhury N, Kasinath BS and Choudhury GG: TGF $\beta$-stimulated microRNA-21 utilizes PTEN to orchestrate AKT/mTORC1 signaling for mesangial cell hypertrophy and matrix expansion. PLoS One 7: e42316, 2012.

79. Kattla JJ, Carew RM, Heljic M, Godson C and Brazil DP: Protein kinase B/Akt activity is involved in renal TGF-beta1-driven epithelial-mesenchymal transition in vitro and in vivo. Am J Physiol Renal Physiol 295: F215-F225, 2008.

80. Meadows KN, Iyer S, Stevens MV, Wang D, Shechter S, Perruzzi C, Camenisch TD and Benjamin LE: Akt promotes endocardial-mesenchyme transition. J Angiogenes Res 1: 2, 2009.

81. Romashkova JA and Makarov SS: NF-kappaB is a target of AKT in anti-apoptotic PDGF signalling. Nature 401: 86-90, 1999.

82. Zhong W, Shen WF, Ning BF, Hu PF, Lin Y, Yue HY, Yin C, Hou JL, Chen YX, Zhang JP, et al: Inhibition of extracellular signal-regulated kinase 1 by adenovirus mediated small interfering RNA attenuates hepatic fibrosis in rats. Hepatology 50: 1524-1536, 2009

83. Ma X, Kumar M, Choudhury SN, Becker Buscaglia LE, Barker JR, Kanakamedala K, Liu MF and Li Y: Loss of the miR-21 allele elevates the expression of its target genes and reduces tumorigenesis. Proc Natl Acad Sci USA 108: 10144-10149, 2011.

84. Chen B, Liu J, Chang Q, Beezhold K, Lu Y and Chen F: JNK and STAT3 signaling pathways converge on Akt-mediated phosphorylation of EZH2 in bronchial epithelial cells induced by arsenic. Cell Cycle 12: 112-121, 2013.

85. Zhao J, Tang N, Wu K, Dai W, Ye C, Shi J, Zhang J, Ning B, Zeng $\mathrm{X}$ and Lin Y: miR-21 simultaneously regulates ERK1 signaling in HSC activation and hepatocyte EMT in hepatic fibrosis. PLoS One 9: e108005, 2014.

86. Huang C, Li J, Ding M, Wang L, Shi X, Castranova V, Ju G and Costa M: Arsenic-induced NFkappaB transactivation through Erks- and JNKs-dependent pathways in mouse epidermal JB6 cells. Mol Cell Biochem 222: 29-34, 2001.

87. Ling M, Li Y, Xu Y, Pang Y, Shen L, Jiang R, Zhao Y, Yang $\mathrm{X}$, Zhang J, Zhou J, et al: Regulation of miRNA-21 by reactive oxygen species-activated $E R K / N F-\kappa B$ in arsenite-induced cell transformation. Free Radic Biol Med 52: $1508-1518,2012$

88. Sandhir R, Gregory E and Berman NE: Differential response of miRNA-21 and its targets after traumatic brain injury in aging mice. Neurochem Int 78: 117-121, 2014.

89. Zhou L, Yang ZX, Song WJ, Li QJ, Yang F, Wang DS, Zhang N and Dou KF: MicroRNA-21 regulates the migration and invasion of a stem-like population in hepatocellular carcinoma. Int J Oncol 43: 661-669, 2013.

90. Zhu Q, Wang Z, Hu Y, Li J, Li X, Zhou L and Huang Y: miR-21 promotes migration and invasion by the miR-21-PDCD4-AP-1 feedback loop in human hepatocellular carcinoma. Oncol Rep 27: 1660-1668, 2012.

91. Siddesha JM, Valente AJ, Yoshida T, SakamuriSS, DelafontaineP, Iba H, Noda M and Chandrasekar B: Docosahexaenoic acid reverses angiotensin II-induced RECK suppression and cardiac fibroblast migration. Cell Signal 26: 933-941, 2014.

92. Reis ST, Pontes-Junior J, Antunes AA, Dall'Oglio MF, Dip N, Passerotti CC, Rossini GA, Morais DR, Nesrallah AJ, Piantino $\mathrm{C}$, et al: miR-21 may acts as an oncomir by targeting RECK, a matrix metalloproteinase regulator, in prostate cancer. BMC Urol 12: 14, 2012.

93. Fan X, Wang E, Wang X, Cong X and Chen X: MicroRNA-21 is a unique signature associated with coronary plaque instability in humans by regulating matrix metalloproteinase-9 via reversion-inducing cysteine-rich protein with Kazal motifs. Exp Mol Pathol 96: 242-249, 2014.

94. Wei J, Feng L, Li Z, Xu G and Fan X: MicroRNA-21 activates hepatic stellate cells via PTEN/Akt signaling. Biomed Pharmacother 67: 387-392, 2013

95. Adam O, Löhfelm B, Thum T, Gupta SK, Puhl SL, Schafers HJ, Böhm M and Laufs U: Role of miR-21 in the pathogenesis of atrial fibrosis. Basic Res Cardiol 107: 278, 2012.

96. Liang H, Zhang C, Ban T, Liu Y, Mei L, Piao X, Zhao D, Lu Y, Chu W and Yang B: A novel reciprocal loop between microRNA-21 and TGF $\beta$ RIII is involved in cardiac fibrosis. Int J Biochem Cell Biol 44: 2152-2160, 2012.

97. Zhu HY, Li C, Bai WD, Su LL, Liu JQ, Li Y, Shi JH, Cai WX, Bai XZ, Jia YH, et al: MicroRNA-21 regulates hTERT via PTEN in hypertrophic scar fibroblasts. PLoS One 9: e97114, 2014. 
98.Pellman J, Lyon RC and Sheikh F: Extracellular matrix remodeling in atrial fibrosis: Mechanisms and implications in atrial fibrillation. J Mol Cell Cardiol 48: 461-467, 2010.

99. Tan AY and Zimetbaum P: Atrial fibrillation and atrial fibrosis J Cardiovasc Pharmacol 57: 625-629, 2011.

100. Babür Güler G, Karaahmet T and Tigen K: Myocardial fibrosis detected by cardiac magnetic resonance imaging in heart failure: Impact on remodeling, diastolic function and BNP levels. Anadolu Kardiyol Derg 11: 71-76, 2011.

101. Csak T, Bala S, Lippai D, Satishchandran A, Catalano D, Kodys K and Szabo G: microRNA-122 regulates hypoxia-inducible factor-1 and vimentin in hepatocytes and correlates with fibrosis in diet-induced steatohepatitis. Liver Int 35: 532-541, 2015.

102.Huang C, Zheng JM, Cheng Q, Yu KK, Ling QX, Chen MQ and $\mathrm{Li}$ N: Serum microRNA-29 levels correlate with disease progression in patients with chronic hepatitis B virus infection. J Dig Dis 15: 614-621, 2014.

103. He X, Xie J, Zhang D, Su Q, Sai X, Bai R, Chen C, Luo X, Gao G and Pan W: Recombinant adeno-associated virus-mediated inhibition of miRNA-21 protects mice against the lethal schistosome infection by repressing both IL-13 and transforming growth factor beta 1 pathways. Hepatology 61: 2008-2017, 2015.
104. Friedman SL: Molecular regulation of hepatic fibrosis, an integrated cellular response to tissue injury. J Biol Chem 275: 2247-2250, 2000

105.Zeng CH, Le W, Ni Z, Zhang M, Miao L, Luo P, Wang R, Lv Z, Chen J, Tian J, et al: A multicenter application and evaluation of the oxford classification of $\operatorname{IgA}$ nephropathy in adult Chinese patients. Am J Kidney Dis 60: 812-820, 2012.

106. Cutroneo KR, White SL, Phan SH and Ehrlich HP: Therapies for bleomycin induced lung fibrosis through regulation of TGF-betal induced collagen gene expression. J Cell Physiol 211: 585-589, 2007.

107. White ES, Atrasz RG, Hu B, Phan SH, Stambolic V, Mak TW, Hogaboam CM, Flaherty KR, Martinez FJ and Kontos CD: Negative regulation of myofibroblast differentiation by PTEN (phosphatase and tensin homolog deleted on chromosome 10). Am J Respir Crit Care Med 173: 112-121, 2006.

108. Varga J and Abraham D: Systemic sclerosis: A prototypic multisystem fibrotic disorder. J Clin Invest 117: 557-567, 2007. 